\title{
CONF-9509344--1
}

\section{NMR SOLUTION STRUCTURES OF ADDUCTS FROM THE BINDING OF POLYCYCLIC AROMATIC DIOL EPOXIDES TO DNA}

by

\section{Cosman, B. E. Hingerty, S. Amin,} S. Broyde, N. E. Geacintov, and D. J. Patel

\section{DISCLAIMER}

\begin{abstract}
This report was prepared as an account of work sponsored by an agency of the United States Government. Neither the United States Government nor any agency thereof, nor any of their employees, makes any warranty, express or implied, or assumes any legal liability or responsibility for the accuracy, completeness, or usefulness of any information, apparatus, product, or process disclosed, or represents that its use would not infringe privately owned rights. Reference herein to any specific commercial product; process, or service by trade name, trademark, manufacturer, or otherwise does not necessarily constitute or imply its endorsement, recommendation, or favoring by the United States Government or any agency thereof. The views and opinions of authors expressed herein do not necessarily state or reflect those of the United States Government or any agency thereof.
\end{abstract}

The submitted manuscript has been authored by Oak Ridge National Laboratory, managed by Lockheed Martin Energy Research Corporation for the U.S. Department of Energy under contract number DE-AC05-96OR22464. Accordingly the U.S. Government retains a nonexclusive, royaltyfree license to publish or reproduce the published form of this contribution, or allow others to do so, for U.S. Government purposes. 
NMR SOLETION STRUCTURES OF ADDUCTS DERIVED FROM THE BINDING OF POLYCYCLIC AROMATIC DIOL EPOXIDES TO DNA.

\author{
M. Cosman ${ }^{1,6}$, B.E. Hingerry ${ }^{2}$, S. Amin ${ }^{3}$, S. Broyde ${ }^{4}$, N.E. Geacintor ${ }^{5}$, \\ and D.J. Parel ${ }^{1}$
}

${ }^{1}$ Cellular Biochemistry and Biophysics Program, Memorial Sloan Kettering Cancer Center, New York. NY 10021. ${ }^{2}$ Health and Safery Research Division, Oak Ridge National Laboratory, Oak Ridge, TN $37831 .{ }^{3}$ American Health Foundation, Valhalla, NY 10595; ${ }^{4}$ Biology Department and ${ }^{5}$ Chemistry Department, New York University, New York, NY 10003. Present address: ${ }^{6}$ Lawrence Livermore National Laboratory, Livemore, CA 94551.

\begin{abstract}
Site-specifically modified oligonucleorides were derived from the reactions of stereoisomeric polycyclic aromatic diol epoxide metabolite model compounds with oligonucleotides of defined base composition and sequence. The NMR solution structures of ten different adducts studied so far are briefly described, and it is shown that stereochemical factors and the nature of the oligonucleotide context of the complementary strands, exert a poweriul influence on the conformational features of these adducts.
\end{abstract}

\title{
INTRODUCTION
}

We have synthesized a variety of site-specifically modified oligonucleotides derived from the covalent binding reactions of different stereoisomeric polycyclic aromatic hydrocarbon diol epoxides (PAHDE) to short DNA fragments of defined base composition and sequence. ${ }^{1}$ Using one- and two-dimensional NMR methods combined with molecular mechanics calculations, we have studied the solution structures of these oligonucleotide adducts. and discovered a striking diversity of stereochemistry-dependent stucaural motifs. ${ }^{2-10}$ A comprehensive picture of the types of conformations of adducts derived from the binding of stereoisomeric PAHDE molecules to duplex DNA is beginning to emerge. ${ }^{2-13}$ In this articie, we provide a short account of our own findings ${ }^{2-10}$ in this area of research.

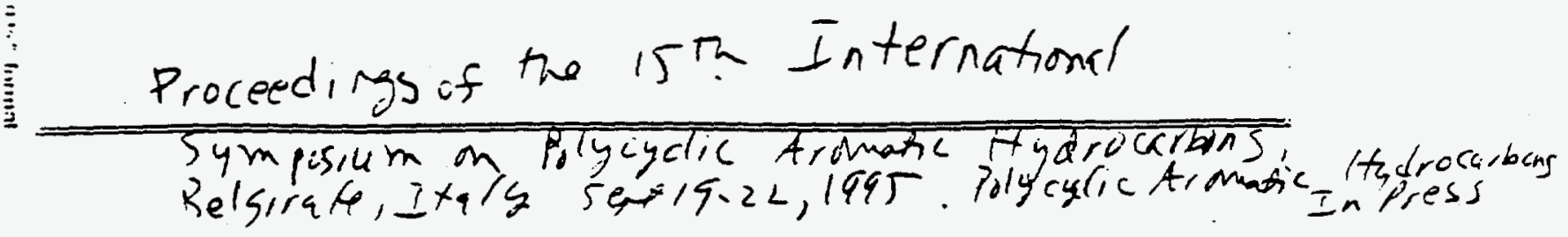




\section{STRUCTURES OF DNA ADDUCTS: BPDE-N ${ }^{2}$-dG LESIONS.}

The $(+)$ - and $(-)$-enantiomers of anti-BPDE (7R,8S-dihydroxy-9S,10R-epoxy- and $7 S, 8 R$-dihydroxy-9R,IOS-epoxy-7,8,9,10-tetrahydrobenzo[a]pyrene, respectively) bind covalently to the exocyclic amino group of guanine residues in DNA ${ }^{14}$ (BPDE- ${ }^{2}$. $\mathrm{dG}$ lesions). There are four stereoisomerically distinct anti-BPDE- $\mathrm{N}^{2}-\mathrm{dG}$ lesions since both (t)- and (-)-anti-BPDE can add trans or cis to the C10 position of anti$\mathrm{BPDE}^{14}$. We have studied the solution NMR conformations of these adducts in the duplex:

\section{$5^{\prime}-\mathrm{d}\left(\mathrm{CCATC}\left[^{\mathrm{BP}} \mathrm{G}\right] \mathrm{CTACC}\right)$ \\ 3'-d(GGTAG--C--GATGG)}

in which the non-modified strand is fully complementary to the anti-BPDE-modified strand; the anti-[BP]- $\mathrm{N}^{2}-\mathrm{dG}$ lesion is denoted by $\left[{ }^{\mathrm{BP}} \mathrm{G}\right]$. The adduct conformations of the stereoisomeric, but chemically identical ( + )-trans- (IOS adduct stereochemistry at C-10 of the BP residue $\left.{ }^{2}\right),(-)-\operatorname{trans}-\left(10 S^{3}\right),(+)-\operatorname{cis}-\left(10 R^{4}\right)$ and $(-)$-cis-anti-[BP]-N ${ }^{2}-$ $\mathrm{dG}$ lesions (IOS) (Cosman et al., in preparation) in duplex I are remarkably different from one another.

The two trans-anti-[BP]dG adducts. In the (t)-trans-and (-)-trans-anti-[BP]dG adducts in duplex $I$, the pyrenyl residues are simated in the minor groove with one face exposed to the aqueous environment. In the (+)-trans-adduct the pyrenyl residue points to the 5 -end of the modified strand, while in the case of the (-)-transadduct, the pyrenyl ring system points toward the 3'-end. ${ }^{2,3}$ This structural motif, i.e. opposite orientations of adducts relative to the modified base reoccurs in other pairs of stereoisomeric adducts derived from chiral enantiomeric diol epoxides. 9,10 The two cis-anti-[BP]dG Adducts. In the (+)- and (-)-cis-anti[BP]- $\mathrm{N}^{2}-\mathrm{dG}$ adducts in $I$ the pyrenyl residues are inserted into the duplex but the modified guanine residues are displaced into the minor groove $\left((+)-c i s-a d d u c t^{4}\right)$ and into the major groove $((-)$-cis-adduct). Furthermore, in the (+)-cis-adduct, the benzylic ring is in the minor groove with the polycyclic aromatic portion pointing towards the major groove. ${ }^{4}$ In the (-)-cis-adduct (M. Cosman, et al., in preparation) the BP assumes the opposite orientation with the benzylic ring situated in the major groove. Thus, the chirality of the two anti-BPDE enantiomers manifests itself in a plane 
perpendicular to the helix axis, rather than along the minor grooves as in the case of the $(t)$-and ()$_{3}$; trans-anti-[BP]dG adducts ${ }^{2,3}$ in sequence I. acstracts. equations

\section{Conformations of [BP]- $\mathrm{N}^{\mathbf{2}}-\mathrm{dG}$ Lesions in Deletion Duplexes}

11-mer/10-mer anti-[BP]dG deletion duplexes. The stalling of polymerases at the sites of the lesions can give rise to slipped, misaligned intermediates that can lead to deletions and point mutations. ${ }^{15}$ As a model system for such extended bulged intermediates, we investigated the high resolution NMR characteristics of sequence $\mathrm{II}$, with the $\mathrm{C}$ opposite the lesion missing in the partner strand ${ }^{5,6}$ (11-mer/10-mer duplex):

$$
\begin{aligned}
& \text { 5'-d(CCATC }{ }^{\text {BP }} \text { G]CTACC) } \\
& \text { 3'-d(GGTAG----GATGG) }
\end{aligned}
$$

The most striking finding is that the (t)-trans-anti-[BP]- $\mathrm{N}^{2}-\mathrm{dG}$ is no longer in the minor groove as in the full duplex ${ }^{2}$ I, but is inserted into the helix with the modified guanine displaced into the major groove. 5 With the stereoisomeric cis-adduct, the base-displaced intercalation conformation prevails in both the normal duplex ${ }^{4} \mathrm{I}$, as well as in the deletion duplex ${ }^{6} \mathrm{I}$; in both cases, the modified guanine residues are displaced into the minor groove. These results suggest that stable $(-1)$ deletion structures can be formed upon extension of slipped frameshift intermediates. Consistent with this conclusion, $\mathrm{Ya}$ et al. ${ }^{16}$ showed that the deletion duplexes II are thermodynamically stabilized by the presence of the BP residues.

\section{BPDE-N $\mathbf{N}^{2}-\mathrm{dG}$ Lesions at Single Strand/Double Strand Junctions.}

13-mer/9-mer partial replication fork model sequence. At the single-strand/double strand junction in a polymerase replication complex, the complementary strand on the 5'-side of the modified template strand is missing. In order to investigate the conformations of $[\mathrm{BP}]-\mathrm{N}^{2}-\mathrm{dG}$ lesions at such junctions, we investigated the solution structure of the following 13-mer/9-mer modified template/primer sequence ${ }^{7}$ :

$$
5^{\prime}-d\left(A A C l^{B P}\right. \text { G]CTACCATCC) }
$$

The primer strand extends up to the lesion site in $\mathbf{M I}$, and there is no complementary 
base. opposite the BP-modifed guanine residue. A detailed analysis of the NMR solution conformations shows, that there is more conformational flexibility in the case of the (-)-trans-adduct in than in the case of the (+)-trans-adduct III. In the latter case; the glycosidic torsion angle of the modified guanine residue assumes a syn rather than the usual anti conformation ${ }^{7}$; the modified guanine is thus displaced, and the pyrenyl ring system of the BP moiety is stacked over the 3 -terminal guanine on the primer strand. This structural motif shares features of base displacement and BP-base stacking with the deletion structures, but employs a syn-modified guanosyl residue. In the (-)-trans-adduct III, there is a striking loss of resolution of the NMR resonances of the protons in the immediate vicinity of the BP-modified guanine residue that extends over $2-3$ bases flanking the lesion on either side. These data suggest a significant conformational heterogeneity in the case of the $(-)$-trans-adduct III and the exact conformation of the BP residue could not be established. ${ }^{7}$

\section{5-Methylchrysene diol epoxide- $\mathrm{N}^{\mathbf{2}}-\mathrm{dG}$ adducts: effects of a methyl group.} Methyl groups, depending on their positions in a polycyclic aromatic ring system, can exert powerful effects on the biological activities of these compounds. ${ }^{17}$ The effects of a methyl group on the solution structure of duplex I containing a $(-)$-transanti-[MC]- $\mathrm{N}^{2}-\mathrm{dG}$ lesion was investigated in detail ${ }^{8}$ ([MC]: residue obtained from the reaction of $1 S, 2 R$-dihydroxy-3R,4S-epoxy-1,2,3,4-tetrahydro-5-methylchrysene, a metabolite of 5-methylchrysene ${ }^{17}$, to $\mathrm{N}^{2}-\mathrm{dG}$ in DNA). The $[\mathrm{MC}]$ residue is situated in the minor groove and points into the $3^{\prime}$-direction of the modified strand, ${ }^{8}$ as in the structurally related (-)-trans-anti-[BP]- $\mathrm{N}^{2}-\mathrm{dG}$ adduct duplex ${ }^{3} \mathrm{I}$. The $-\mathrm{CH}_{3}$ group, however, causes a buckling of the [MC]-modified dG-dC base pair, a local widening of the minor groove and a compression in the major groove, thus leading to a wedge-shaped local structure and a large bend at the binding site. ${ }^{8}$

\section{Conformational Adduct Heterogeneity.}

In the case of the (+)-cis-[BP]- $\mathrm{N}^{2}-\mathrm{dG}$ adduct duplexes $\mathrm{I}$, there is evidence of a second, minor conformation $\left(-15 \%\right.$ at $\left.10^{\circ} \mathrm{C}\right)$, that bears the characteristics of a non-intercalated structure. NMR exchange crosspeaks suggest that the major basedisplaced intercalative conformation and this minor adduct conformation are in 
exchange with one another. ${ }^{4}$ Fountain and Krugh ${ }^{11}$ studied the solution structure of duplexes dwith, the $(t)-2$ transianti-[BP]- $\mathrm{N}^{2}-\mathrm{dG}$ lesion in the sequence context 5 ......T $\left[{ }^{\mathrm{BP}} \mathrm{G}\right] \mathrm{C}$......-3' which differed from the $\left.5^{\prime}-\ldots . . . \mathrm{C}^{\mathrm{BP}} \mathrm{G}\right] \mathrm{C} . . . .-3^{\prime}$ sequence context in $\mathrm{I}$. In the $\left.5^{\prime}-\ldots . . . T{ }^{B P} \mathrm{G}\right] \mathrm{C} . . . . .3^{\prime}$ sequence context, a minor groove structure with the pyrenyl residue pointing into the 5'-direction of the modified strand was the major observed conformation, ${ }^{11}$ consistent with the structure observed in duplexes ${ }^{2}$ of $I$. However, a minor structure in equilibrium with the major structure was also observed; this conformational heterogeneity was attributed to the dT base on the 5'side. of the lesion, ${ }^{11}$ since only the minor groove structure is observed when $\mathrm{dC}$ bases flank the modified guanine residue on both sides. ${ }^{2}$ Conformational heterogeneity that is sensitive to base sequence context may thus be an important structural feature of such adducts.

\section{PAH DIOL EPOXIDE-N6-dA ADDUCTS.}

We synthesized a pair of stereoisomeric adducts, derived from the binding of $4 r, 3 t$-dihydroxy-2,1t-epoxy-1,2,3,4-tetrahydrobenzo[c]phenanthrene (anti-BPhDE) to the exocyclic amino group of adenine in the duplex ${ }^{18}$ :

$$
\begin{aligned}
& \text { 5'-d(CT CTC } \left.\left.{ }^{B P h} A\right] C T T C C\right) \\
& \text { 3'-d(GAGAG T GAAGG) }
\end{aligned}
$$

The NMR solution structures of the (+)- and (-)-trans adducts 9,10 IV derived from the reaction of the $4 S, 3 R, 2 R, 1 S$ - and $4 R, 3 S, 2 S, 1 R$-BPhDE enantiomers to the oligonucleotide d(CTCTCACTTCC), respectively, exhibit structural motifs quite different from those exhibited by the $[B P]-N^{2}-d G$ adducts. ${ }^{2-4}$ These structures 9,10 are the closest to those of classical intercalation complexes (modified classical intercalation) normally associated with the insertion of flat polynuclear aromatic drug molecules between adjacent base pairs of duplex DNA. The aromatic BPh residues in both the (+)-trans- and (-)-trans-anti-[BPh]- $\mathrm{N}^{6}$-dA adducts IV, with T opposite the lesions in the complementary strands, are stacked essentially between the $T$ and G residues on the complementary strands. ${ }^{9,10}$ In contrast to the base-displaced intercalative conformations observed in the case of the cis-anti-[BP]- $\mathrm{N}^{2}-\mathrm{dG}$ adducts, ${ }^{4}$ the modified base is not displaced, and all 11 base pairs in IV are intact. 


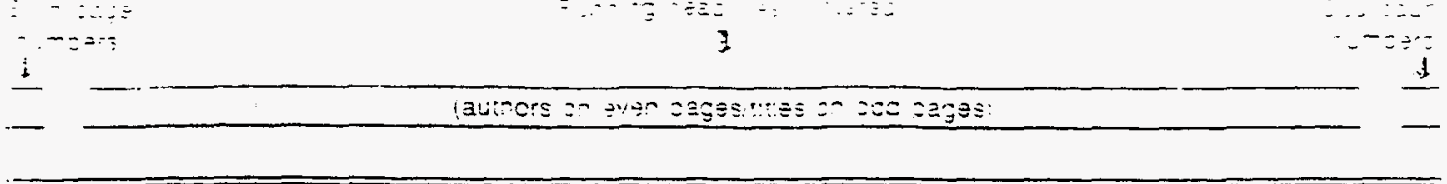

The adducts are characterized by strikingly different orientations in that the $\mathrm{BPh}$ residue is -intercalated on the 5 -side of the modified adenine residue in the $(+)$ trans-, and on the 3 -side in the case of the (-)-trans-adduct. 9,10 These differences, just as in the case of the opposite orientations of the $(+)$-trans- and $(-)$-trans-anti$[B P]-N^{2}-d G$ lesions, ${ }^{2,3}$ are a consequence of the chiral characteristics of the enantiomeric $\mathrm{PAH}$ diol epoxide adduct precursors. In order to accomodate the bulky $\mathrm{BPh}$ residues, the helix is stretched, and the base pairs at the site of the lesion are buckled in opposite directions.

Recently, the NMR solution structures of $(-)$-trans-anti- and $(+)$-trans-anti$[B P]-N^{6}-d A$ lesions ${ }^{12,19}$ opposite $G$, and a (-)-trans-syn-[BP]-N $N^{6}-d A$ lesion ${ }^{13}$ and a $(-)$-trans-anti-[BP]- $\mathrm{N}^{6}-\mathrm{dA}$ lesion. ${ }^{20,21}$ opposite the normal complementary $\mathrm{T}$, were determined. The conformations are intercalative in all four cases without base displacement, and the sites of insertion on the 5'- or 3'-side of the modified adenine residues, ${ }^{12,19-21}$, are consistent with those observed with the stereochemically analogous (t)- and (-)-trans-anti-[BPh]- $\mathrm{N}^{6}-\mathrm{dA}$ adducts ${ }^{9,10}$ in duplex $\mathrm{IV}$.

\section{CONCLUSIONS}

The types of structural motifs discovered up till now are summarized in Table 1.

The rapidly growing number of established PAH diol epoxide-DNA adduct structures ${ }^{2-13,19-21}$ will ultimately lead to a better understanding of the mechanisms of mutations associated with this class of PAH metabolites. The remarkable effects of the different configurations of substituents about the four chiral carbon centers in the benzylic ring on adduct conformation indicates that the impact of stereochemical factors on the biological activities of PAH diol epoxides will be eventually elucidated.

\section{ACKNOWLEDGEMENTS}

This work was supported by NIH Grants CA 46533 (D.J.P.), CA 20851 (N.E.G.), CA 28038 (S.B.) and by the Department of Energy Grants DE-FGO2-86ER-60405 (N.E.G.) and DE-FGO2-90ER60931 (S.B.), and DOE Contract DE-AC05-840R21400 with Martin-Marietta Energy Systems and DOE OHER Field work Proposal ERKP931 to B.E.H. Computations were carried out at NERSC (DOE) and SDSC (NSF). 


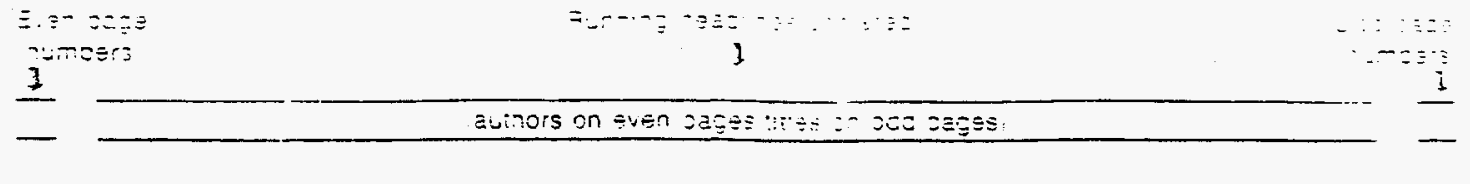

\section{REFERENCES}

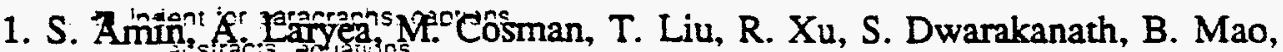
R.G. Harvey, S.S. Hecht, and N.E. Geacintov. This volume.

2. M. Cosman, C. de los Santos, R. Fiala, B.E. Hingerty, V. Ibanez, L.A. Margulis, D. Live, N.E. Geacintov, S. Broyde, and D.J. Patel, Proc. Natl. Acad. Sci. (USA), 89, 1914 (1992).

3. C. de los Santos, M. Cosman, B.E. Hingerty, V. Ibanez, L.A. Margulis, N.E. Geacintov, S. Broyde, and D.J. Patel, Biochemistry, 31, 5245 (1992).

4. M. Cosman, C. de los Santos, R. Fiala, B.E. Hingerty, V. Ibanez, E. Luna, R.G. Harvey, N.E. Geacintov, S. Broyde, and D.J. Patel, Biochemistry, 32, 4145 (1993).

5. M. Cosman, R. Fiala, B.E. Hingerty, S. Amin, N.E. Geacintov, S. Broyde, and D.J. Patel, Biochemistry, 33, 11507 (19َ94).

6. M. Cosman, R. Fiala, B.E. Hingerty, S. Amin, N.E. Geacintov, S. Broyde, and D.J. Patel, Biochemistry, 33, 11518 (1994).

7. M. Cosman, B.E. Hingerty, N.E. Geacintov, S. Broyde, and D.J. Patel, Biochemistry (1995), in press.

8. M. Cosman, R. Xu, B.E. Hingerty, S. Amin, R.G. Harvey, N.E. Geacintov, S. Broyde, and D.J. Patel, Biochemistry, 34, 6247 (1995).

9. M. Cosman, R. Fiala, B.E. Hingerty, A. Laryea, H. Lee, R.G. Harvey, S. Amin, N.E. Geacintov, S. Broyde, and D.J. Patel, Biochemistry, 32, 12488 (1993).

10. M. Cosman, A. Laryea, R. Fiala, B.E. Hingerty, S. Amin, N.E. Geacintov, S. Broyde, and D.J. Patel, Biochemistry, 34, 1295 (1995).

11. M.A. Fountain and T.R. Krugh, Biochemistry, 34, 3152 (1995).

12. E.J. Schurter, H.J.C. Yeh, J.M. Sayer, M.K. Lakshman, H. Yagi, D.M. Jerina, and D.G. Gorenstein, Biochemistry, 34, 1364 (1995).

13. E.J. Schurter, J.M. Sayer, T. Oh-hara, H.J.C. Yeh, H. Yagi, B.A. Luxon, D.M. Jerina, and D.G. Gorenstein, Biochemistry, 34, 9009 (1995).

14. S.C. Cheng, B.D. Hilton, J.M. Roman, and A. Dipple, Chem. Res. Toxicol., 2, 334 (1989).

15. T.A. Kunkel, Biochemistry, 29, 8003 (1990).

16. N.-Q. Ya, S. Smimov, M. Cosman, S. Bhanot, V. Ibanez, and N.E. Geacintov, in Structural Biology: The State of the Art. Proceedings of the 8th Conversation, edited by R.H. Sarma and M.H. Sarma (Adenine Press, Schenectady, NY, 1994), Vol. 2, pp. 349-366.

17. S.S. Hecht, A.A. Melikian, and S. Amin, Accts. Chem. Res. 19, 174 (1986).

18. A. Laryea, M. Cosman, J.-M. Lin, T. Liu, R. Agarwal, S. Sminov, S. Amin, R.G. Harvey, A. Dipple, and N.E. Geacintov, Chem. Res. Toxicol., 8, 444 (1995).

19. .H.J.C. Yeh, J.M. Sayer, X. Liu, A.S. Altieri, R.A. Bird, M.K. Lakshman, H. Yagi, E.J. Schurter, D.G. Gorenstein, and D.M. Jerina, Biochemistry, in press.

20. I.S. Zegar, S.J. Kim, P. Horton, C.M. Harris, T.M. Harris, and M.P. Stone, J. Biomol. Struct. \& Dynam., 12, Abstract a271 (1995).

21. X. Liu, H. Yeh, J. Sayer, M.K. Lakshman, and D.M. Jerina, private communication. 
Table 1. Observed Structural Motifs For Conformations of PAH-DNA Adducts ${ }^{\mathrm{a}}$

\begin{tabular}{|c|c|c|c|c|}
\hline Structural Motif & $\begin{array}{c}\text { PAH } \\
\text { Orientation }\end{array}$ & Adduct & $\begin{array}{l}\text { DNA } \\
\text { Context }\end{array}$ & Reference \\
\hline Minor groove & $5^{\prime}$-orientation & $(+)$-trans-[BP]-N $N^{2}-d G$ & normal duplex & Refs. 2, 11. \\
\hline Minor groove & 3 -orientation ${ }^{b}$ & 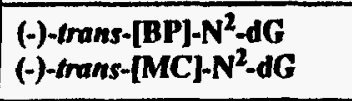 & $\begin{array}{l}\text { normal duplex } \\
\text { normal duplex }\end{array}$ & $\begin{array}{l}\text { Ref. } 3 \\
\text { Ref. } 8\end{array}$ \\
\hline $\begin{array}{l}\text { Base-Displaced } \\
\text { Intercalation }\end{array}$ & $\begin{array}{l}\text { from minor to } \\
\text { major groove }\end{array}$ & $\begin{array}{l}(+)-c i s-[B P]-N^{2}-d G \\
(+)-c i s-[B P]-N^{2}-d G\end{array}$ & $\begin{array}{l}\text { normal duplex } \\
\text { (-1)deletion duplex }\end{array}$ & $\begin{array}{l}\text { Ref. } 4 \\
\text { Ref. } 6\end{array}$ \\
\hline $\begin{array}{l}\text { Base-Displaced } \\
\text { Intercalation }\end{array}$ & $\begin{array}{l}\text { from major to } \\
\text { minor groove }\end{array}$ & 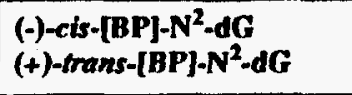 & $\begin{array}{l}\text { normal duplex } \\
\text { (-1)deletion duplex }\end{array}$ & $\begin{array}{l}\text { Cosman et al (1996) } \\
\text { Ref. } 5\end{array}$ \\
\hline $\begin{array}{l}\text { Modified Classical } \\
\text { Intercalation }\end{array}$ & 5'-insertion & 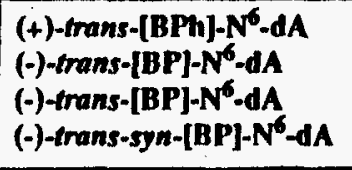 & $\begin{array}{l}\text { normal duplex } \\
\text { mismatch, duplex } \\
\text { normal duplex } \\
\text { normal duplex }\end{array}$ & $\begin{array}{l}\text { Ref. } 9 \\
\text { Ref. } 12 \\
\text { Ref. 20, } 21 \\
\text { Ref. 13 }\end{array}$ \\
\hline $\begin{array}{l}\text { Modified Classical } \\
\text { Intercalation }\end{array}$ & 3'-insertion & $\begin{array}{l}\text { (-)-trans-[BPh]dA } \\
\text { (+)-trans-[BP]dA }\end{array}$ & $\begin{array}{l}\text { normal duplex } \\
\text { mismatch, duplex }\end{array}$ & $\begin{array}{l}\text { Ref. } 10 \\
\text { Ref. } 19\end{array}$ \\
\hline $\begin{array}{l}\text { Stacking with } \\
\text { terminal primer base } \\
\text { at single strand - } \\
\text { duplex junction; } \\
\text { modified } G \text { is syn }\end{array}$ & $\begin{array}{l}\text { Irom modified } \\
\text { template strand } \\
\text { towards primer } \\
\text { strand }\end{array}$ & $(+)-$ trans-[BP]-N $N^{2}-d G$ & $\begin{array}{l}\text { 13-mer/9-mer (mo- } \\
\text { dified template)- } \\
\text { (primer) junction }\end{array}$ & Ref. 7 \\
\hline $\begin{array}{l}\text { Conformational } \\
\text { heterogeneity }\end{array}$ & multiple & (-)-trans-[BP]-N $-d G$ & 13-mer/9-mer & Ref. 7 \\
\hline
\end{tabular}

"All adducts derived Arom anti-PAH diol epoxides (DE 2), unless noted "syn" (DE 1). [BP] = from benzo[a]pyrene diof epoxide; $[\mathrm{BPh}]=$ from benzo[c]phenanthrene diol epoxide. $[\mathrm{MC}]=$ from 5-methylchrysene diol epoxide. "Orientation of aromatic PAH residue relative to modified base and the 5'- or 3'-direction of the modified DNA strand. 'Orientation is from benzylic ring to the pyrenyl moiety. Modified base displaced into major or minor groove. 